\title{
Mobile Learning Features Preferred: An Examination of Students in The United Arab Emirates
}

\author{
Jason D. Johnson ${ }^{{ }^{*}}$, Cara Williams ${ }^{2}$ \\ ${ }^{7}$ Zayed University, UNITED ARAB EMIRATES \\ ${ }^{2}$ Emirates College for Advanced Education, UNITED ARAB EMIRATES \\ *CORRESPONDENCE: jason.johnson@zu.ac.ae
}

\begin{abstract}
The purpose of the current study was to examine the preferred mobile learning features higher education Emirati students use to make sense of mathematics and to determine if these Emirati students valued a mobile device as an essential tool to learn mathematics. Both students and instructors used the Texas Instruments Nspire: Computer Algebra System (CAS) App in a semester mathematics course. The app has such features as enter expressions in proper mathematics notation, import images, dynamically linked notes, share work across platforms (emails, iTunes, Dropbox, etc.), and save documents to mobile device. Participates included sixty-three undergraduate students enrolled in a mathematics course at Zayed University (Dubai campus, United Arab Emirates). Based on a pre- and post-survey, students' positive perspectives of mathematics increased, negative perspectives decreased, and instructor influence on mobile learning increased. The pre- and post-questionnaire revealed an increase in the participants' opinion that mobile learning is an essential tool to help make sense of mathematics.
\end{abstract}

Keywords: Middle East, United Arab Emirates, TI-Nspire CAS App, university mathematics

\section{INTRODUCTION}

Smartphone, iPad, and Android are sample mobile devices include features many K-12 mathematics teachers and educators use, such as texting, voice command, and multimedia capabilities. How are higher education faculty utilizing the features of mobile devices in the teaching and learning of university mathematics (not including courses solely for mathematics education majors or developmental mathematics courses, which prepare students for university level mathematics)? For the current study, mobile learning is defined as the ability to learn anywhere at any time facilitated by mobile devices (Traxler, 2009). Compared to laptops and computer workstations, mobile devices are cheaper, portable, and physically less obtrusive, especially during collaborative work (Allen, 2011). The popularity of mobile devices has prompted education reformers to shine a light on these mobile technologies as vehicles suitable for transforming education and learning for the 21st century (Allen, 2011). The National Council of Teachers of Mathematics (NCTM) (1998), in the Principles and Standards for School Mathematics, states "technology enriches the range and quality of investigations by providing a means of viewing mathematical ideas from multiple perspectives” (p. 25).

\section{K-12 Mathematics Research Studies}

There are an abundance of research studies examining K-12 students using mobile learning to explore mathematics (Baya'a \& Daher, 2011; Bokhove \& Drijvers, 2010, 2011; Bull \& McCormick, 2011; CaytonHodges, Feng, Pan, \& Vezzu, 2013; Franklin \& Peng, 2008; Harrison, 2013; Hewitt, 2012; Kalloo \& Mohan,

Article History: Received 7 September $2019 \bullet$ Revised 19 May $2020 \bullet$ Accepted 22 May 2020

(C) 2020 by the authors; licensee Modestum Ltd., UK. Open Access terms of the Creative Commons Attribution 4.0 International License (http://creativecommons.org/licenses/by/4.0/) apply. The license permits unrestricted use, distribution, and reproduction in any medium, on the condition that users give exact credit to the original author(s) and the source, provide a link to the Creative Commons license, and indicate if they made any changes. 
2012; Kim, Lim, Choi, \& Hahn, 2012; Loch, Galligan, Hobohm, \& McDonald, 2011; McDaniel, Agarwal, Huelser, McDermott, \& Roediger, 2011; Moyer-Packenham, Salkind, \& Bolyard, 2008; Polly, 2011; Tsuei, Chou, \& Chen, 2013). The research studies that follow will support the notion of K-12 students from various countries using a mobile device to enhance learning. In Trinidad and Tobago, Kalloo and Mohan (2012) examined the benefits of how mobile learning could help students at-risk improve secondary mathematics grades in the Caribbean. Of the Games, Lesson, and Example features of mobile learning assessed, the Games feature was used most by the students, implying that game-based learning may be a worthy approach for forthcoming mobile learning applications. Roberts and Vänskä (2011) utilized the Nokia Mobile Learning for Mathematics Project to increase South African students' grades in mathematics. Kiger, Herro, Prunty (2012) investigated the impact of mobile learning on American elementary students' mathematics achievement. The comparison group used Everyday Math and flashcards for daily practice and the mobile learning intervention (MLI) group used web applications for the iPod touch for daily practice. After controlling for covariates, such as prior achievement, home iPod touch use, and previous teacher, the MLI group performed higher than the comparison students on a postintervention multiplication test, concluding that adding a mobile device to existing curriculum may improve student achievement. Finally, in Greece, Zaranis, Kalogiannakis, and Papadkis (2013) examined Kindergarten students using mobile technology to develop mathematical understanding. Results concluded that tablet supported learning and the teaching of Realistic Mathematics, with the use of educational software for tablets, produced improved learning outcomes for students when compared to traditional teaching methods based on the Greek Cross Thematic Curriculum Framework. The studies above demonstrate a wide range of research studies for students using mobile learning, from various countries, to increase student understanding and/or achievement in mathematics.

Some research studies made use of students using their mobile device to access the World-Wide-Web to make sense of mathematics. For instance, Meyer (2014) examined the use of iPads in a middle grades mathematics classroom in Denmark to determine the influence of students using the Internet (web-resources) to improve mathematics achievement. Some studies allowed students to use blended mobile learning and a mobile device for assessment during instruction. One study conducted in Israeli Occupied Territories examined the use of blended mobile learning. In other words, the learner or teacher determines when and how to use their mobile devices to accomplish a task. Peled and Schocken (2014) explored elementary learners and teachers using a blended mobile learning program - SlateMath. SlateMath is a comprehensive program that supports the teaching and learning of mathematics for elementary learners and includes such features as anyplace/anywhere learning, customized learning, and adaptive learning just to name a few. Last, students using a mobile device for Quick Response assessment. Rikala (2014) explored students, in various Finland elementary schools, using a mobile device to generate Quick Response codes during mathematics lessons.

\section{Higher Education Mathematics and Mobile Learning}

Many higher education institutions have reported on internal studies, however, few are disseminated in peer-reviewed journals (i.e., Zayed University, Higher Colleges of Technology, University of Central Florida, Haifa University, Abilene Christian University, Stanford University, Islamic Azad University, University of Wollongong, and University of Technology-Malaysia). In the United Arab Emirates, all Federal Higher Education Institutions initiated the use of mobile learning. The Higher Colleges of Technology (HCT) created iBooks for general education mathematics courses. Such iBooks contain elaborate visuals, embedded videos, and touch-screen dictionaries. HCT created many valuable and creditable internal documents to support mobile learning, although, none were disseminated in peer-reviewed journals. Not to disregard such reports, disseminated research is extremely important to influence education at a systemic level.

A benchmark was set to explore research studies in only peer-reviewed journals that target higher education students using a mobile device in the teaching and learning of university mathematics (not including mathematics education and developmental mathematics). Likewise, the present study was only interested in mobile learning used in university mathematics (not including Internet technologies and computer software). In the end, no such articles were discovered. Next, an Internet web search was conducted for universities that use a mobile device in the department of mathematics (not including courses for only mathematics education majors or developmental mathematics courses, which prepare students for university level mathematics). Twenty-two institutions were identified. It could not be determined how each mathematics department made use of the mobile device. For instance, did students use the mobile device solely as a calculator? As a textbook? Or to complete enrichment activities? Additionally, there is lack of published 
research in peer-reviewed journals that focus on higher education and students in the United Arab Emirates using mobile learning to explore university mathematics.

The purpose of the present research study was to explore university Emirati students using a mobile device to make sense of mathematics. Teaching the $21^{\text {st }}$ century student may require changes in how mathematics is taught. Thus, allowing students to use a mobile device in the mathematics classroom, could be the change. Researchers in other countries have conducted studies to determine students' perceptions for using a mobile device to make sense of mathematics (Kalloo \& Mohan, 2012; Kiger, Herro, \& Prunty, 2012; Meyer, 2014; Peled \& Schocken, 2014; Rikala, 2014 Roberts \& Vänskä, 2011; Zaranis, Kalogiannakis, \& Papadkis, 2013). However, such a study is needed in the UAE. No research study has explored mobile learning features students prefer to make sense of mathematics. For instance, do students like using a touchscreen to make sense of mathematics? The following research study was designed to explore this topic. The research questions are: (1) Do Emirati students value a mobile device as a beneficial tool to learn mathematics? and (2) Which mobile learning features do Emirati students use to make sense of mathematics?

\section{METHOD}

Grounded theory was used as a framework to guide the research study. According to Patton (2002), grounded theory "focuses on the process of generating theory rather than particular theoretical content" ( $p$. 125). An additional aspect of grounded theory is to test emergent themes. In other words, grounded theory will allow the research team to explore emergent themes identified in the data. Furthermore, Glaser (2001) noted that grounded theory is not only synonymous with qualitative research but can be applied with "any data or combination of data" (p. 7). The notation that grounded theory can be used as a framework to guide quantitative research, will allow the research team to explore the emergent themes generated from the quantitative data. Qualitative and quantitative data were determined to be most appropriate for answering the research questions. Data tools for the current research study included teacher-created activities, a preand post-survey, and a pre- and post-questionnaire.

\section{Participants of Study}

Participants in the study have been identified as undergraduate Emirati students majoring in business. Since each member of the research team were teaching the same mathematics courses, the decision was made that these courses would be the unit of analysis. Furthermore, the participates were selected based on them registering for mathematics sections that the research team were assigned. All courses were homogenous. One researcher was responsible for one female section $(n=23)$ and one male section $(n=16)$, while the other researcher facilitated one female section $(n=24)$. Total participates for the study was $n=63$. The two research team members were required to download the TI-Nspire CX CAS app and TI-Nspire CX Teacher Software (for the laptop). The Teacher Software allowed the research team to develop the needed teacher-created activities. Each participant was only required to download the TI-Nspire CX CAS app to their iPad.

\section{Data}

\section{Pre- and post-questionnaire}

A pre- and post-questionnaire allowed the research team to explore student opinions about using mobile learning to make sense of mathematics and which features students liked and not like in their effort to make sense of mathematics. The pre-questionnaire had one question to identity students' opinion about using mobile learning to make sense of mathematics. The post-questionnaire had three questions, including the same question as the pre-questionnaire and two additional questions. The additional questions required students to elaborate on features, while using the mobile device, that were beneficial and not beneficial for them to make sense of mathematics.

\section{Student completed teacher-created activities}

The research team created one activity for each of the four Units (Unit 1 - percentages, constant and percentage growth, and functions; Unit 2 - unit conversions, simple interest, supply \& demand, and cost \& revenue functions; Unit 3 - compound interest and exponential \& logarithmic functions; and Unit 4 - cost \& revenue functions and quadratic functions). Students completed the teacher-created activities as part of an iterative process. As students completed one activity while using the mobile device to make sense of mathematics, the next activity would be created using student strengths from the previous activity. After 
several readings of the activities, mobile device features were identified, which were then used to create the next unit activity. Each research member read through all three sections and recorded mobile device features. Next, each research member switched sections, completed another read through, and created new mobile device features. In the end, each section had two sets of mobile device features. Each research member compiled the mobile device features created from their sections. These mobile device features were then scrutinized for common themes and completed student activities allowed the research team to examine student learning based on the implementation of the teacher-created activities.

\section{Pre- and post-survey}

The pre- and post-survey allowed the research team to explore the students' opinions about learning mathematics with and without technology to add to the overall profile of the students position regarding mathematics before and after completing the questionnaires and surveys. The pre- and post-survey consisted of twenty-two identical questions to determine if mobile learning influenced students' opinions about learning mathematics. Participants answered each question based on a 5-point Likert scale. Such questions on the preand post-survey are (the number indicates the question number on the pre- and post-survey): (question 14) I prefer studying mathematics to studying for other courses, (9) Time seems to go slow when I am in mathematics class, and (22) I hate going to mathematics class? Dr. Vivian La Ferla, Professor of Mathematics and Computer Science and Educational Studies at Rhodes Island College, USA, approved the use her research team's survey on student position toward mathematics. In their research study, students' position toward culture and mathematics and the influence of ethnomathematics on students' position about mathematics were investigated. Additionally, Dr. La Ferla provided a treatment that consisted of culture/ethnomathematics to determine if the treatment influenced students' opinions about learning mathematics. The research team determined that such a survey was appropriate, since the survey solely focused on students' position for learning mathematics. The treatment for the current study was mobile learning.

\section{Analysis of Data}

All data was triangulated with both research questions: Do Emirati students value a mobile device as a beneficial tool to learn mathematics? and Which mobile learning features do Emirati students use to make sense of mathematics? and The analysis of all data contained four phases. Phase one, several readings of the all data were conducted. By doing so, any emergent themes were identified. Phase two, another set of readings was conducted to code the data by identifying emergent themes, resulting in two sets of codes for each type of data. The reason for the two sets of codes was to determine if the data were coded the same (Patton, 2002). Phase three, another set of readings was conducted to code all the data without identifying the previous codes from phase one or two. After additional scrutiny of the codes in phases two and three, introductory codes were identified (Patton, 2002). Phase four, contained the final set of readings to code the data without identifying the introductory codes. After further inspection of the introductory codes and phase four codes, final codes were recognized.

\section{RESULTS AND DISCUSSION}

The results of the two research questions in the current study will be addressed separately.

Research Question 1: Do university Emirati students value a mobile device as a beneficial tool to learn mathematics?

The first inquiry on the pre- and post-questionnaire focused on the importance of mobile devises as a beneficial tool to learn mathematics. Of the 63 participants, 22 returned the pre-questionnaire and 20 returned the post-questionnaire. The first inquiry on the questionnaire emphasized the students' opinion to make sense of mathematics using a mobile device. The results showed an $8 \%$ increase in students who responded yes, a mobile device helped make sense of mathematics, $3 \%$ decrease in students who replied no, a mobile device did not help make sense of mathematics, and a $5 \%$ decrease in students who were undecided. Of the students who felt mobile learning did not help make sense of mathematics, the three themes that emerged from the teachercreated activities data were: (1) students preferred to use pencil, (2) paper and a calculator was easier to use, and (3) mobile learning makes learning mathematics more difficult. One student wrote: "solving mathematical problems is much easier without using the smart device, I like it the old way." The student is referring to completing mathematics problems the old way-using pencil and paper - and finds it easier to solve problems without using a mobile device. Another student wrote, "No, the TI-Nspire app is a difficult app because if we forget something, and need to add it, we should redo the steps again. And I think that it is easier to do it on 
INT ELECT J MATH ED

$\underline{\text { Table 1. Pre-Post Questionnaire Results for Question } 1}$

\begin{tabular}{lcccccc}
\hline & \multicolumn{3}{c}{ Pre } & & \multicolumn{2}{c}{ Post n=20 } \\
\hline & 3 & 2 & 1 & 3 & 2 & 1 \\
\hline $\begin{array}{l}\text { Is mobile learning an essential tool } \\
\text { for making sense of mathematics? }\end{array}$ & $77 \%$ & $18 \%$ & $5 \%$ & $85 \%$ & $15 \%$ & $0 \%$ \\
\hline
\end{tabular}

Note. $3=$ Yes $/ 2=$ No $/ 3=$ Undecided

Table 2. Student replies to question 2 on the post-questionnaire

\begin{tabular}{lcc}
\hline \multicolumn{2}{l}{ What did you like about using mobile learning to help you make sense of mathematics? } \\
\hline Graphs & Percentage of Students \\
& $23 \%$ & \\
Determine intersection point & $23 \%$ & \\
Calculate max & $23 \%$ & \\
Calculate zero(s) & $15 \%$ & $25 \%$ \\
Split-screen (using table) & $23 \%$ & $20 \%$ \\
Calculator & $7 \%$ & $5 \%$ \\
$\quad$ Analyze graph feature & & $25 \%$ \\
\hline Tables & & $5 \%$ \\
\hline Easy to calculate formulas & $20 \%$ \\
Simlify formulas & $5 \%$ \\
Notes page & $5 \%$ \\
\hline Gives the answer fast & \\
\hline Solve equations & \\
\hline Convert fractions to decimals easily & \\
\hline Father found it easy to use too & \\
\hline
\end{tabular}

paper because most students are more comfortable using paper." The student pointed out that using the app is challenging and there is a preference for using pencil and paper. A third student wrote: "No, because I think it makes math more difficult, more than it really is." Like the student above, this student has the opinion that mobile learning makes mathematics more problematic when mathematics is not.

Of the $5 \%$ of participants who were undecided on the pre-questionnaire, one theme was consistent in the data, which was the idea that apps can be confusing. One student wrote:

"I think that a mobile device (such as iPad, Android, smartphones, etc.) can help students make sense of mathematics depending on how the student is using the app and how the app is designed to help. Some App's do encourage students to learn more and see their progress, whereas some Apps can be so complicated to use and wastes time trying to figure how to use it instead of how to answer the mathematics question. So, I do agree and disagree at the same time because there are some advantages and disadvantages too. Personally, I prefer studying mathematics without a mobile device (such as iPad, Android, smartphones, etc.) because that's how I learned math as a child."

Students agree that mobile learning is vital to learn mathematics, however, there are two components that should work together; (1) how the learner will use the mobile device to make sense of mathematics and (2) how the software on the mobile device was designed to help students learn. Table 1 summarizes the results of the pre- and post-questionnaire.

Our results were consistent with other researchers from countries in the Middle East.

Research Question 2: Which mobile learning features do university Emirati students use to make sense of mathematics?

The post-questionnaire was identical to the pre-questionnaire with two additional questions. The two additional questions related to students' opinions regarding like and dislike for using mobile learning to make sense of mathematics. Question 2 of the post-questionnaire, required students to report on what they liked about using mobile learning to make sense of mathematics (Table 2).

As shown in Table 2, 65\% of the participants liked using the graphs. Since graphs include various characteristics, determining what students found most useful with graphs was important. According to the 
Table 3. Student replies to question 3 on the post-questionnaire

\begin{tabular}{lc}
\hline & Percentage of Students \\
\hline Need to modify graph view window & $30 \%$ \\
\hline Hates using iPad & $10 \%$ \\
\hline Not compatible with iPhone & $10 \%$ \\
\hline Having to redo steps (if there is an error) & $5 \%$ \\
\hline Too complicated to use & $5 \%$ \\
\hline Whe consuming & $5 \%$ \\
\hline Need more practice with the device & $5 \%$ \\
\hline Was not able to identify a dislike & $10 \%$ \\
\hline
\end{tabular}

8. [5 Marks] Sultan and Ahmed are interested in investing 300.50 AED for 5 years. Below are the investment options.

\begin{tabular}{|l|l|l|l|}
\hline Amount & Rate & Years & Type \\
\hline AED 300.50 & $2.9 \%$ & 5 & Compounded Continuously \\
\hline AED 300.50 & $0.9 \%$ & 5 & Simple Interest \\
\hline
\end{tabular}

\begin{tabular}{|c|c|c|c|}
\hline \multicolumn{3}{|c|}{ Compound Interest } \\
\hline \multicolumn{2}{|c|}{ Amount } & Rate & Years \\
\hline $300.50 \mathrm{AED}$ & $1.9 \%$ & 5 \\
\hline Value of $\boldsymbol{m}$ & Amount of $\boldsymbol{F}_{\boldsymbol{t}}$ \\
\hline $\mathbf{1}$ & \multicolumn{2}{|}{} \\
\hline $\mathbf{2}$ & \\
\hline $\mathbf{4}$ & \\
\hline $\mathbf{1 2}$ & \\
\hline $\mathbf{5 2}$ & \\
\hline $\mathbf{6 0}$ & \\
\hline $\mathbf{8 0}$ & \\
\hline $\mathbf{9 0}$ & \\
\hline
\end{tabular}

Figure 1. Question 8 on unit 3 teacher-created activity

data, $23 \%$ of the Emirati students used calculating the intersection point, maximum point, and polynomial zero(s) were most effective to make sense of mathematics. Other mobile learning likes the Emirati students used to make sense of mathematics were tables $(25 \%)$ and notes $(25 \%)$. The tables allow students to view data in a tabular format, while the notes have similar characteristics as a word-processor (students have an opportunity to create and edit written text).

Question 3 of the post-questionnaire allowed students to list dislikes for using mobile learning to make sense of mathematics (Table 3 ).

According to the data, $35 \%$ of the participants did not have a dislike for using mobile learning to make sense of mathematics. Having to modify the view-window for the graphs was the next dislike with $30 \%$. The next three dislikes, with $10 \%$ each, for using mobile learning to make sense of mathematics was a dislike for using iPad, TI-Nspire CX app not compatible with iPhone, and need more practice with the mobile device.

Of the 63 participants, 34 completed question 8 on Unit 3 teacher-created activity (Figure 1). Question 8 required students to complete a table using various compound interest scenarios, where the number of compounds change. The intent of the question was for students to use mobile learning to complete the task. Since mobile learning was used, the task required was accomplished quickly with a touch screen.

The results indicated that approximately, $27 \%$ of the students completed the task using the graph and table features (Method A), 35\% used the method of replacing the value for the number of compounds into the compound interest formula and repeated until task was complete (Method B), and 38\% could not be determined. Of the students who implemented Method A, one student wrote: "I used calculate, graphs, and table to complete the chart." Another student wrote: "To complete the chart, I used the graph and table." Both students used the idea of graphing the compound interest formula, where the independent variable is the number of compounds. Then, using the mobile learning device, inserted a table that quickly identified various changing values for $m$ (number of compounds). However, some students used a different method to complete the task. Of the students who used Method B, one student wrote: "I calculated each one [compound interest] alone." A second student wrote: "I used the equation over and over again, while changing the m." The above students used their mobile device to complete the task by calculating each compound interest value by changing the various values for $m$ (number of compounds). 


\section{Ali wants to start a healthy food business and he has determined the profit for each box of fruits/vegetables sold is estimated at:}

$$
P(x)=-0.2 x^{2}+1252 x-59000
$$

a) [4 Marks] Determine the number of boxes Ali must sell to make a profit of 635.20 AED. If a formula is not used, explain how you determined your answer.

Figure 2. Question 1 (part a) on unit 4 teacher-created activity

The same 34 higher participants completed question 1 (part a) on the Unit 4 teacher-created activity (Figure 2). In Unit 4, instructors introduced the idea of the Computer Algebra System (CAS) on the mobile device. CAS had "advanced features as, symbolic manipulation, constructing geometric representations, and exploring multiple representations (i.e., algebraically and graphically) dynamically all on one screen" (Johnson, 2010, p. 44). For the problem, students were asked to determine the number of boxes Ali needed to sell to make a profit of 635.20 AED. To accomplish the task, students should have created the equation $635.20=-0.2 x^{2}+1252 x-59000$ and determined a realistic value for $x$. The goal was to allow students to use their mobile device to solve the problem using any method (i.e., quadratic formula, graphing, CAS, etc.). Figure 2 shows question 1 on the Unit 4 teacher-created activity.

The results revealed that $38 \%$ used the quadratic formula to solve for the number of boxes (Method A), while 35\% used CAS (equation solver) (Method B), and 27\% used a graph (Method C). Of the students who Method A, one student wrote:

$$
\begin{gathered}
\text { “635.20 }=-0.2 x^{2}+1252 x-59000 \\
\mathrm{a} \quad \mathrm{b} \quad \mathrm{c} \\
0=-0.2 x^{2}+1252 x-59635.20 \\
\frac{-1252-\sqrt{1252^{2}-4(-0.2)(-59635.2)}}{2(-0.2)} \text { and } \frac{-1252+\sqrt{1252^{2}-4(-0.2)(-59635.2)}}{2(-0.2)} \\
x_{7}=6212 \text { and } \underline{x}_{2}=48 ”
\end{gathered}
$$

Another student replied:

$$
\begin{aligned}
& \text { "635.20 }=-0.2 x^{2}+1252 x-59000 \\
& 0=-0.2 x^{2}+1252 x-59000-635.20 \\
& 0=-0.2 x^{2}+1252 x-59635.20 \\
& x=\frac{-b \pm \sqrt{b^{2}-4 a c}}{2 a} \mid \begin{array}{l}
x_{1}=47.99 \\
x_{2}=6212.01
\end{array} \\
& \text { Ali must sell } \\
& 48 \text { boxes to } \\
& \text { make a profit" }
\end{aligned}
$$

Both students used the quadratic formula to determine the number of boxes Ali needed sell. Both students calculated two different values that yielded a profit of $635.20 \mathrm{AED}$; and realized 47.99 boxes would be most realistic for Ali. Of the students who used Method B, one student wrote, "I used the app, calculator to solve this question, solve $\left(635.20=-0.2 x^{2}+1252 x-59000, x\right)$," while another student answered, "I used the app and typed: $\operatorname{solve}\left(0=-0.2 x^{2}+1252 x-59635.20, x\right)$." These students also used their mobile device to generate a solution, whereas using the CAS feature.

Last were the students who used Method C. One student wrote: "using the graph, I found Ali will make a profit when he makes 48 boxes" and another responded, "I will use the app and graph the function to get the answer.

Of the 63 participants, 49 returned the pre-survey and 44 returned the post-survey. The survey contained questions to determine students' position on the teaching and learning of mathematics. The survey was analyzed using percentages of responses on a 5-point Likert scale. Whether or not the experiences were 
Table 4. Pre- and Post-Survey Results for Positive Perspectives of Mathematics

\begin{tabular}{|c|c|c|c|c|c|c|c|c|c|c|}
\hline \multirow[t]{2}{*}{ Positive Perspectives } & \multicolumn{5}{|c|}{$\begin{array}{l}\text { Pre- } \\
\text { Test } \\
\mathrm{n}=49\end{array}$} & \multicolumn{5}{|c|}{$\begin{array}{c}\text { Post- } \\
\text { Test } \\
\text { n=44 }\end{array}$} \\
\hline & 5 & 4 & 3 & 2 & 1 & 5 & 4 & 3 & 2 & 1 \\
\hline Mathematics is a course I love? & $41 \%$ & $41 \%$ & $12 \%$ & $6 \%$ & $0 \%$ & $52 \%$ & $29 \%$ & $9 \%$ & $8 \%$ & $2 \%$ \\
\hline $\begin{array}{l}\text { I enjoy discussing mathematics with } \\
\text { my friends? }\end{array}$ & $20 \%$ & $31 \%$ & $23 \%$ & $20 \%$ & $6 \%$ & $21 \%$ & $36 \%$ & $16 \%$ & $18 \%$ & $9 \%$ \\
\hline $\begin{array}{l}\text { I wish mathematics class was longer } \\
\text { (more time in class)? }\end{array}$ & $2 \%$ & $10 \%$ & $17 \%$ & $62 \%$ & $10 \%$ & $2 \%$ & $21 \%$ & $27 \%$ & $36 \%$ & $14 \%$ \\
\hline I like mathematics? & $35 \%$ & $47 \%$ & $12 \%$ & $4 \%$ & $2 \%$ & $43 \%$ & $38 \%$ & $14 \%$ & $5 \%$ & $0 \%$ \\
\hline I like taking mathematics exams? & $16 \%$ & $39 \%$ & $12 \%$ & $23 \%$ & $10 \%$ & $9 \%$ & $43 \%$ & $22 \%$ & $22 \%$ & $7 \%$ \\
\hline Mathematics is interesting for me? & $10 \%$ & $16 \%$ & $29 \%$ & $37 \%$ & $8 \%$ & $36 \%$ & $48 \%$ & $9 \%$ & $7 \%$ & $0 \%$ \\
\hline I love to study mathematics? & $29 \%$ & $43 \%$ & $10 \%$ & $16 \%$ & $2 \%$ & $34 \%$ & $39 \%$ & $16 \%$ & $11 \%$ & $0 \%$ \\
\hline $\begin{array}{l}\text { I prefer studying mathematics to } \\
\text { studying for other courses? }\end{array}$ & $27 \%$ & $27 \%$ & $18 \%$ & $24 \%$ & $4 \%$ & $23 \%$ & $48 \%$ & $16 \%$ & $13 \%$ & $0 \%$ \\
\hline Mathematics is a fun class? & $27 \%$ & $37 \%$ & $20 \%$ & $14 \%$ & $2 \%$ & $25 \%$ & $50 \%$ & $18 \%$ & $7 \%$ & $0 \%$ \\
\hline I feel joyful in mathematics classes? & $23 \%$ & $43 \%$ & $21 \%$ & $10 \%$ & $4 \%$ & $25 \%$ & $39 \%$ & $34 \%$ & $2 \%$ & $0 \%$ \\
\hline \multirow[t]{2}{*}{$\begin{array}{l}\text { I would like to spend most of my } \\
\text { study time doing mathematics? }\end{array}$} & $10 \%$ & $28 \%$ & $27 \%$ & $27 \%$ & $8 \%$ & $9 \%$ & $27 \%$ & $32 \%$ & $30 \%$ & $2 \%$ \\
\hline & $22 \%$ & $33 \%$ & $18 \%$ & $\mathbf{2 2} \%$ & $\mathbf{5 \%}$ & $\mathbf{2 5 \%}$ & $38 \%$ & $19 \%$ & $14 \%$ & $3 \%$ \\
\hline
\end{tabular}

Note. $5=$ Completely Agree $/ 4=$ Agree $/ 3=$ Undecided $/ 2=$ Disagree $/ 1=$ Completely Disagree

positive or negative is unknown, however, through further analysis of the survey data, students appear to have progressed into a fondness for learning mathematics.

Of the 22 questions on the pre- and post-survey, 11 questions addressed students' positive perspectives of mathematics. Students' positive perspectives of mathematics increased from the pre- to post-survey. When the "Completely Agree" and "Agree" categories were averaged, the largest increase resulted from the question: "Mathematics is interesting to me?", with an average percentage change of $58 \%$. One may conclude that the use of mobile device and TI-Nspire CX CAS app features amplified student interest in mathematics. The second largest average percent change came from the question: "I prefer studying mathematics to studying for other courses?" with a change of $17 \%$. Table 4 contains the questions and percentages of student responses addressing positive perspectives of mathematics.

Of the 22 questions on the pre- and post-survey, 9 questions addressed students' negative perspectives of mathematics. Students' negative perspectives of mathematics decreased from the pre- to post-survey. When the "Completely Agree" and "Agree" categories were averaged, the largest decrease resulted from the questions: "Mathematics is challenging work for me?" and "Mathematics scares me?", with an average percentage change of $9 \%$. One may conclude that the decreased of the challenge and fear of mathematics may be due to the accessibility of mobile device and TI-Nspire CX CAS app features to make sense of mathematics. The second largest average percent change came from the question: "Mathematics makes me uncomfortable?" with a change of $8 \%$. Table 5 contains the questions and percentages of student responses addressing negative perspectives of mathematics. 
$\underline{\text { Table 5. Pre- and Post-Survey Results for Negative Perspectives of Mathematics }}$

\begin{tabular}{|c|c|c|c|c|c|c|c|c|c|c|}
\hline \multirow[t]{2}{*}{ Negative Perspectives } & \multicolumn{5}{|c|}{$\begin{array}{l}\text { Pre- } \\
\text { Test } \\
n=49\end{array}$} & \multicolumn{5}{|c|}{$\begin{array}{c}\text { Post- } \\
\text { Test } \\
\mathrm{n}=44\end{array}$} \\
\hline & 5 & 4 & 3 & 2 & 1 & 5 & 4 & 3 & 2 & 1 \\
\hline $\begin{array}{c}\text { Students' life would be more enjoyable } \\
\text { without math class? }\end{array}$ & $8 \%$ & $20 \%$ & $23 \%$ & $37 \%$ & $12 \%$ & $7 \%$ & $18 \%$ & $23 \%$ & $39 \%$ & $13 \%$ \\
\hline $\begin{array}{c}\text { I am bored when I study } \\
\text { mathematics? }\end{array}$ & $4 \%$ & $4 \%$ & $21 \%$ & $58 \%$ & $14 \%$ & $2 \%$ & $7 \%$ & $18 \%$ & $57 \%$ & $16 \%$ \\
\hline $\begin{array}{c}\text { Mathematics class is challenging } \\
\text { work for me? }\end{array}$ & $12 \%$ & $15 \%$ & $17 \%$ & $49 \%$ & $8 \%$ & $7 \%$ & $9 \%$ & $18 \%$ & $55 \%$ & $11 \%$ \\
\hline $\begin{array}{c}\text { Time seems to go slow when I am in } \\
\text { mathematics class? }\end{array}$ & $10 \%$ & $16 \%$ & $29 \%$ & $37 \%$ & $8 \%$ & $7 \%$ & $21 \%$ & $23 \%$ & $40 \%$ & $9 \%$ \\
\hline $\begin{array}{l}\text { Mathematics is the course that scares } \\
\text { me the most? }\end{array}$ & $8 \%$ & $25 \%$ & $10 \%$ & $43 \%$ & $14 \%$ & $7 \%$ & $20 \%$ & $7 \%$ & $52 \%$ & $14 \%$ \\
\hline $\begin{array}{c}\text { Mathematics makes me } \\
\text { uncomfortable? } \\
\end{array}$ & $4 \%$ & $14 \%$ & $20 \%$ & $46 \%$ & $14 \%$ & $5 \%$ & $5 \%$ & $22 \%$ & $59 \%$ & $9 \%$ \\
\hline Mathematics scares me? & $6 \%$ & $27 \%$ & $4 \%$ & $43 \%$ & $20 \%$ & $2 \%$ & $16 \%$ & $14 \%$ & $50 \%$ & $18 \%$ \\
\hline $\begin{array}{c}\text { My least favorite class is } \\
\text { mathematics? }\end{array}$ & $10 \%$ & $15 \%$ & $12 \%$ & $43 \%$ & $21 \%$ & $7 \%$ & $4 \%$ & $21 \%$ & $47 \%$ & $21 \%$ \\
\hline I hate going to mathematics class? & $4 \%$ & $2 \%$ & $12 \%$ & $64 \%$ & $19 \%$ & $7 \%$ & $2 \%$ & $11 \%$ & $52 \%$ & $28 \%$ \\
\hline & $7 \%$ & $15 \%$ & $16 \%$ & $47 \%$ & $14 \%$ & $6 \%$ & $11 \%$ & $17 \%$ & $50 \%$ & $15 \%$ \\
\hline
\end{tabular}

Note. $5=$ Completely Agree $/ 4=$ Agree $/ 3=$ Undecided $/ 2=$ Disagree $/ 1=$ Completely Disagree

Table 6. Pre- and Post-Survey Results of Instructor Influence

\begin{tabular}{|c|c|c|c|c|c|c|c|c|c|c|}
\hline \multirow[t]{2}{*}{ Instructor Influence } & \multicolumn{5}{|c|}{$\begin{array}{l}\text { Pre- } \\
\text { Test } \\
n=49\end{array}$} & \multicolumn{5}{|c|}{$\begin{array}{c}\text { Post- } \\
\text { Test } \\
\text { n=44 }\end{array}$} \\
\hline & 5 & 4 & 3 & 2 & 1 & 5 & 4 & 3 & 2 & 1 \\
\hline $\begin{array}{l}\text { I have had teachers who encouraged } \\
\text { students to use portable devices (such } \\
\text { as iPad, Android, smartphones, etc.) } \\
\text { to make sense of mathematics? }\end{array}$ & $37 \%$ & $35 \%$ & $6 \%$ & $16 \%$ & $6 \%$ & $43 \%$ & $48 \%$ & $3 \%$ & $4 \%$ & $3 \%$ \\
\hline $\begin{array}{l}\text { I have had teachers who taught } \\
\text { mathematics using portable devices } \\
\text { (iPad, Android, smartphones, etc.)? }\end{array}$ & $28 \%$ & $37 \%$ & $6 \%$ & $22 \%$ & $6 \%$ & $36 \%$ & $39 \%$ & $14 \%$ & $11 \%$ & $0 \%$ \\
\hline & $33 \%$ & $36 \%$ & $6 \%$ & $19 \%$ & $6 \%$ & $40 \%$ & $44 \%$ & $8 \%$ & $8 \%$ & $1 \%$ \\
\hline
\end{tabular}

Note. $5=$ Completely Agree $/ 4=$ Agree $/ 3=$ Undecided $/ 2=$ Disagree $/ 1=$ Completely Disagree

Of the 22 questions on the pre- and post-survey, 2 questions addressed instructor influence of mobile devices in mathematics. Instructor influence of mobile learning in mathematics increased from the pre- to post-survey. When the "Completely Agree" and "Agree" categories were averaged, the largest increase resulted from the question: "I have had teachers who encouraged students to use portable devices (such as iPad, Android, smartphones, etc.) to make sense of mathematics?" with an average percentage change of $19 \%$. The result is not a surprise, as the students had an experience with a teacher using mobile learning during instruction. The second largest average percent change came from the question: "I have had teachers who taught mathematics using portable devices (iPad, Android, smartphones, etc.)?" with a change of 10\%. Table 6 contains the questions and percentages of student responses addressing instructor influence of mobile learning in mathematics.

\section{MOBILE LEARNING OR TI NsPire TECHNOLOGY}

One premise of the study was to examine if university Emirati students value a mobile device as a beneficial tool to learn mathematics. Data from the pre- and post-questionnaire revealed an $8 \%$ increase in favor of mobile devices, from $77 \%$ to $85 \%$. Pre- and post-questionnaire results were consistent with the notion that the undergraduate Emirati students believe mobile learning is critical to learn mathematics. The preand post-questionnaire emphasized the Emirati students' opinions to make sense of mathematics using a mobile device. The second premise of the study was to investigate the mobile learning features used by the 
higher education Emirati students to make sense of mathematics. An analysis of the results of Unit 3 teacher created activity concluded that over a quarter of the participants reported that they used such mobile learning features as graphs and tables to complete the activity. Therefore, the question needed to be asked is, "are these features truly mobile learning or TI-Nspire technology?" Likewise, the results of question 2 of the postquestionnaire reveled that almost three-quarters of the participants reported that the mobile learning features they liked using were graphs, while one-quarter of participants enjoyed using both tables and notes. Again, are these features associated with mobile learning or TI-Nspire technology? As stated before, typical features of mobile learning consist of import images, one-to-one touch, share work across platforms (emails, iTunes, Dropbox, etc.), and save documents to mobile device. However, TI-Nspire technology has such features as enter expressions in proper mathematics notation, construct geometric representation, explore multiple representations dynamically all on one screen, dynamically linked notes, import images, save documents to calculator, and wirelessly share work (with the aid of TI-Navigator).

The above analysis revealed, the higher education Emirati students reported using such features associated with TI-Nspire calculator (i.e., TI-Nspire CX, TI-Nspire CAS, TI-Nspire CX CAS). Though, two mobile learning features omitted from the TI-Nspire calculator the one-to-one touch (touchscreen) and share work across platforms (emails, iTunes, Dropbox, etc.). Since TI-Nspire calculator lacks two features, traditionally associated with mobile learning, is it possible that the TI-Nspire calculator can be considered a mobile device? Zelkowski (2011) presented a compelling case why the TI-Nspire calculator should be considered the most valuable mobile device for the mathematics student and teacher. Zelkowski further explains:

\begin{abstract}
"There are capabilities and features within the TI-Nspire CAS Touchpad unobtainable with any other mobile device on the market today. However, much of the apprehensions to mobile devices in the classroom stem from students' ability to communicate with each other through email, text or photo messaging, or browsing the web. This mobile device alleviates all of these concerns. Classrooms equipped with the wireless navigator system allow teachers to instantly monitor, collect and assess, or present students' live feed from their handhelds with the Navigator. Students can communicate with the teacher's computer and display using the classroom projector. Yet, students cannot communicate with each other [wirelessly], thus keeping students on task since they do not have the ability to text, email, or browse the web. They are wirelessly limited to communicate within the classroom and with the teacher only" (p. 42).
\end{abstract}

The main reason the TI-Nspire calculator does not have the one-to-one touch feature is due to examination restrictions. According to testing agencies (i.e., Scholastic Aptitude Test (SAT), Advanced Placement (AP), International Baccalaureate (IB) exams, and American College Test (ACT)), calculators with touch-screens are not permitted. If TI-Nspire calculator was equipped with a touch-screen, students who use TI-Nspire calculator, would need to purchase an additional calculator that could be used during such examinations. Next, share work across platforms. The TI-Nspire calculator does allow students to share with other TI-Nspire calculator users, of course, using a connecting cord. An additional sharing feature, only used with the TINavigator, allows a TI-Nspire calculator user to wirelessly send and receive documents typically from/to the teacher. The TI-Nspire calculator does allow users to share files.

The last mobile learning feature that will certify the TI-Nspire calculator is a mobile device is the ability to learn anywhere at any time. As previous stated, Traxler (2009) define mobile learning as the ability to learn anywhere at any time mediated by a mobile device. TI-Nspire calculator users can learn anywhere using such programs as: Graphs, Spreadsheets, Notes, Data and Statistics, Geometry, Calculator, and Vernier DataQuest. All these programs can be utilized on the go.

As previously stated, the TI-Nspire calculator is a unique mobile learning device used in the teaching and learning of mathematics. The higher education Emirati students value a mobile learning device with such features as graph capability, explore multiple representations dynamically all on one screen, dynamically linked notes, save documents to calculator, and ability to learn anywhere.

\title{
LIMITATIONS AND RECOMMENDATIONS
}

There are several limitations to the study. Students need more opportunities to work with mobile learning features to make sense of mathematics. Students reported using TI-Nspire technology features, but did 
students understand the difference between the mobile device and the software on the device? Another limitation was using two mathematics faculty who had limited experience with the TI-Nspire CX app. Faculty need time to explore the benefits for using mobile learning to make sense of mathematics, such as allowing students to create videos, use other apps (besides the TI-Nspire CX), and watch videos. Finally, there was a need for students to have had additional training using the TI-Nspire CX app. Many students expressed the need to attend a session on how to use the mobile device with the TI-Nspire CX app. With more training, faculty could have created tutorial videos to help students use the mobile learning factures.

Future research is needed to explore mobile learning used in university mathematics (i.e., abstract algebra, advanced calculus, or real analysis). Currently, mobile learning at the tertiary level seems to be restricted to mathematics education and developmental mathematics courses. Mathematics education and developmental mathematics have proven great success in helping students learn mathematics while using mobile learning. Research using mobile learning in university mathematics is highly needed to explore how mobile learning benefits students in higher level mathematics courses. A plan to continue the current research with additional faculty at other institutions is of paramount importance. Working with mathematicians and mathematics educators would be a great combination to further the current study.

\section{CONCLUSION}

The studied explored the notion of university Emirati students position for the use of a mobile device in the learning of mathematics and the student's views for which mobile learning features were used to make sense of mathematics. It was reviled that the Emirati students did value a mobile device to make sense of mathematics. However, when students determined their preferred mobile learning features used to make sense of mathematics, such features were associated with the TI-Nspire calculator, rather than traditional mobile learning features. Since the mobile learning features identified by students were associated with the TI-Nspire, we believe that the TI-Nspire could be recognized as a mobile device.

\section{ACKNOWLEDGEMENT}

Research supported by Zayed University's Center for Educational Innovation Mobile Learning Research Fund, Activity Code R14131.

\section{Disclosure statement}

No potential conflict of interest was reported by the authors.

\section{Notes on contributors}

Jason D. Johnson - Zayed University, United Arab Emirates.

Cara Williams - Emirates College for Advanced Education, United Arab Emirates.

\section{REFERENCES}

Baya'a, N., \& Daher, W., (2009). Student perceptions of mathematics learning using mobile phones. Teaching Mathematics and Its Applications. In L. Ricci \& V. Boccardi (Eds.). Proceedings of the International Conference on Mobile and Computer Aided Learning (IMCL), 22-24 April (pp.1-9).

Bokhove, C., \& Drijvers, P. (2010). Digital tools for algebra education: Criteria and evaluation. International Journal of Computers for Mathematical Learning, 15(1), 45-62. https://doi.org/10.1007/s10758-0109162-x

Bokhove, C., \& Drijvers, P. (2011). Effects of feedback conditions for an online algebra tool. In M. Joubert, A. Clark-Wilson, \& M. McCabe (Eds.). Proceedings of the Tenth International Conference for Technology in Mathematics Teaching (ICTM) (pp. 81-86).

Bull, P. H., \& McCormick, C. (2011). Mobile learning: Enhancing a pre-algebra course at a communitycollege with text messaging. International Journal of Instructional Technology and Distance Learning, 8(1), 25-36. 
Butler, A. C., \& Roediger, H. L. (2007). Testing improves long-term retention in a simulated classroom setting. European Journal of Cognitive Psychology, 19(4-5), https://doi.org/10.1080/09541440701326097

Cayton-Hodges, G. A., Feng, G., \& Pan, X. (2015). Tablet-based math assessment: What can we learn from math apps? Educational Technology \& Society, 18(2), 3-20.

Franklin, T., \& Peng, L.-W. (2008). Mobile math: Math educators and students engage in mobile learning. Journal of Computing in Higher Education, 20(2), 69-80. https://doi.org/10.1007/s12528-008-9005-0

Glaser, B. G. (2001). The future of grounded theory. Grounded Theory Review, 1, 1-8. https://doi.org/10.4324/9780203793206-1

Harrison, T. R. (2013). The evaluation of iPad applications for the learning of mathematics (Masters of Science Thesis), North Carolina State University.

Hewitt, D. (2012). Young students learning formal algebraic notation and solving linear equations: Are commonly experienced difficulties avoidable? Educational Studies in Mathematics, 81(2), 139-159. https://doi.org/10.1007/s10649-012-9394-x

Johnson, J. D. (2010). Prospective middle grades teachers of mathematics using hand-held CAS technology to create rich mathematical task. Journal of Mathematical Sciences and Mathematics Education. 5, 4254 .

Kalloo, V., \& Mohan, P. (2012). Correlation questionnaire data with actual usage of data in a mobile learning study for high school mathematics. The Electronic Journal of e-Learning, 10(1), 76-89.

Kiger, D., Herro, D., \& Prunty, D. (2012). Examining the influence of a mobile learning intervention on third grade math achievement. Journal of Research on Technology in Education, 45(1), 61-82. https://doi.org/10.1080/15391523.2012.10782597

Kim, Y., Lim, C., Choi, H., \& Hahn, M. (2012, August). Effects on training mathematics problem solving behaviors using a tablet computer. Paper presented at the 2012 IEEE International Conference on Teaching, Assessment and Learning for Engineering (TALE), Hong Kong. https://doi.org/10.1109/TALE.2012.6360299

Loch, B., Galligan, L., Hobohm, C., \& McDonald, C. (2011). Learner-centred mathematics and statistics education using netbook tablet PCs. International Journal of Mathematical Education in Science and Technology, 42(7), 939-949. https://doi.org/10.1080/0020739X.2011.611910

McDaniel, M. A., Agarwal, P. K., Huelser, B. J., McDermott, K. B., \& Roediger III, H. L. (2011). Test enhanced learning in a middle school science classroom: The effects of quiz frequency and placement. Journal of Educational Psychology, 103(2), 399-414. https://doi.org/10.1037/a0021782

Meyer, B. (2014). iPads in learning: The web of change. In M. B. Nunes \& M. McPherson (Eds.), The International Conference on e-Learning. Proceedings of the Multi Conference on Computer Science and Information Systems (MCCSIS), Lisbon, Portugal, 15-19 July (pp. 13-20). International Association for Development of the Information Society.

Moyer-Packenham, P. S., Salkind, G., \& Bolyard, J.J. (2008). Virtual manipulatives used by K-8 teachers for mathematics instruction: Considering mathematical, cognitive, and pedagogical fidelity. Contemporary Issues in Technology and Teacher Education, 8(3), 202-218.

NCTM. (1998). Principles and Standards of School Mathematics. Reston, VA: National Council of Teachers of Mathematics.

Peled, S., \& Schocken, S. (2014). Mobile learning and early age mathematics. In I. A. Sánchez, \& P. Isaías (Eds.), Proceedings of the 10 $0^{\text {th }}$ International Conference on Mobile Learning 2014. Proceedings of the 10th International Conference on Mobile Learning 2014, Madrid, Spain, 19 - 25 February (pp.19 - 25). International Association for Development of the Information Society (IADIS).

Polly, D. (2011). Technology to develop algebraic reasoning. Teaching Children Mathematics, 17(8), 472-478.

Rikala, J. (2014). Evaluating QR codes case studies using a mobile learning framework. In I. A. Sánchez, \& P. Isaias (Eds.), Proceedings of the 10 ${ }^{\text {th }}$ International Conference on Mobile Learning 2014. Proceedings of the 10 ${ }^{\text {th }}$ International Conference on Mobile Learning 2014, Madrid, Spain, 19 - 25 February (pp. 199206). International Association for Development of the Information Society (IADIS).

Roberts, N., \& Vänskä, R. (2011). Challenging assumptions: Mobile learning for mathematics project in south Africa. Distance Education, 32(2), 243-259. https://doi.org/10.1080/01587919.2011.584850 
Santos, I. M. (2013). Integrating personal mobile devices in teaching: The impact on student learning and institutional support. Learning and Teaching in Higher Education: Gulf Perspectives, 10(2), 43-63.

Santos, I. M. (2014). Mobile devices in higher education classrooms: Challenges and opportunities. In J. Keengwe (Eds). Promoting active learning through the integration of mobile and ubiquitous technologies (pp. 37-54). https://doi.org/10.4018/978-1-4666-6343-5.ch003

Santos, I. M., \& Ali, N. (2012). Beyond classroom: The uses of mobile phones by female students. International Journal of Information and Communication Technology Education, 8(2), 63-75. https://doi.org/10.4018/jicte.2012010107

Traxler. J. (2009). The evolution of mobile learning. In R. Guy (Ed.), The evolution of mobile teaching and learning (pp. 1-14). Santa Rosa, CA: Informing Science Press.

Tsuei, M., Chou, H.-Y., \& Chen, B.-S. (2013). Measuring usability of the Mobile Mathematics curriculum-based measurement application with children. In A. Marcus (Ed.), Design, User Experience, and Usability. Health, Learning, Playing, Cultural, and Cross-Cultural User Experience (pp. 304-310). https://doi.org/10.1007/978-3-642-39241-2_34

Vavoula, G., \& Sharples, M. (2009). Meeting the challenges in evaluating mobile learning: A 3-level evaluation framework. International Journal of Mobile and Blended Learning, 1(2), 54-75. https://doi.org/10.4018/jmbl.2009040104

Zaranis, N., Kalogiannakis, M., \& Papadakis, S. (2013). Using mobile devices for teaching realistic mathematics in kindergarten education. Creative Education, 4(7A1), 1-10. https://doi.org/10.4236/ce.2013.47A1001

Zelkowski, J. (May, 2011). The TI-Nspire CAS: A happy-medium mobile device for Grades 8-16 mathematics classrooms. TechTrends: Linking Research and Practice to Improve Learning, 55(3), 40-47. https://doi.org/10.1007/s11528-011-0496-6 